\title{
Analisis Penambahan Doping Magnesium Pada Material Superkonduktor FeSe Dengan Metode Reaksi Padatan Dalam Tabung Tertutup
}

\author{
Analysis of Magnesium Doping on FeSe Superconductor Material Using Solid-State Reaction \\ Method in Sealed Tubes
}

\author{
Muhammad Ilham Maulana1,*, Agung Imaduddin², Sigit Dwi Yudanto2, Rifqi Aulia Tanjung1 \\ ${ }^{1}$ Teknik Material dan Metalurgi, Jurusan Ilmu Kebumian dan Lingkungan, Institut Teknologi Kalimantan, Balikpapan \\ 2 Pusat Penelitian Metalurgi dan Material - LIPI, Gedung 470, Kawasan PUSPIPTEK Serpong, Kota Tangerang Selatan
}

\author{
* Penulis koresponden : 06151024@student.itk.ac.id \\ Tel.: +62-81535357601; fax.:+62-5428530800 \\ Diterima: 16 Agustus 2019; Direvisi: 20 Oktober 2019; Disetujui: 21 Oktober 2019 \\ DOI: 10.25299/saintis.2019.vol19(02).3185
}

\begin{abstract}
Abstrak
Ketergantungan manusia terhadap teknologi memasuki Revolusi Industri 4.0 sangat tinggi. Contoh penerapan inovasi di bidang teknologi informasi salah satunya adalah superkomputer dari material superkonduktor. Material superkonduktor identik dengan material non ferromagnetik karena sifatnya diamagnetis sempurna. Namun, sejak ditemukannya material superkonduktor berbasis logam ferromagnetik, penelitian terus dikembangkan, salah satunya material superkonduktor FeSe. Beberapa parameter yang perlu diperhatikan pada pembuatan material superkonduktor FeSe untuk memperoleh sifat superkonduktor terbaiknya diantaranya komposisi stoikiometri, penambahan doping, dan proses pembuatan material FeSe seperti proses pemaduan dan sintering. Dalam penelitian ini, pengaruh variasi doping Mg akan dianalisis terhadap sifat superkonduktor, morfologi, dan fasa yang terbentuk pada material superkonduktor FeSe. Material superkonduktor FeSe dibuat dengan metode reaksi padatan dalam tabung tertutup (Powder in Sealed Tube) secara insitu. Temperatur sintering yang digunakan $845^{\circ} \mathrm{C}$ yang ditahan selama 6 jam, dengan kenaikan temperatur $7^{0} \mathrm{C} /$ menit dari temperatur kamar, dan laju pendinginan normalizing. Kandidat material superkonduktor terbaik terdapat pada sampel $\mathrm{Mg}_{0.01} \mathrm{Fe}_{0.99} \mathrm{Se}$. Didapatkan Temperatur kritis $(\mathrm{Tc})_{\text {onset }}=15.42 \mathrm{~K}$ dan $\mathrm{Tc}_{\text {zero }}=5.4 \mathrm{~K}$. Morfologi sampel menunjukkan kristalisasi besar. Lalu, persentase fraksi volume fasa superkonduktor nya juga merupakan yang terbesar yaitu $81.99 \%$.
\end{abstract}

Kata Kunci: Doping Magnesium, Reaksi Padatan, Sintering, Superkonduktor FeSe, Temperatur Kritis

\begin{abstract}
Human dependence on technology into the Industrial Revolution 4.0 is very high. Example, the application of innovations in information technology is supercomputer from superconducting materials. Superconducting materials are identical from non-ferromagnetic materials because tend perfectly diamagnetic. However, since ferromagnetic-metal-based superconducting material discovered, research continues to be developed, like FeSe superconductor material. Some parameters that need to be considered in making FeSe material to obtain the best superconductor properties include stoichiometric composition, doping addition, and process of making FeSe materials like synthesis and sintering treatment. In this study, the effect of Mg-doped variations will be analyzed towards properties of superconductors, morphology, and phases formed in FeSe superconducting materials. $\mathrm{Mg}_{x} \mathrm{Fe}_{1-x} \mathrm{Se}$ made by solid-state reaction method in sealed tube (Powder in Sealed Tube) "insituely". The sintering temperature used $845^{\circ} \mathrm{C}$ which held for 6 hours, with $7^{\circ} \mathrm{C} /$ minute temperature rise from room-temperature and normalizing cooling rate used. The best candidate superconducting material came from $\mathrm{Mg}_{0.01} \mathrm{Fe}_{0.99} \mathrm{Se}$, obtained critical temperature (Tc) onset $=15.42 \mathrm{~K}$, and $T c_{z e r o}=5.4 \mathrm{~K}$. Sample morphology shows a large crystallization. Then, the percentage fraction of the superconducting phase was also the largest, which is $81.99 \%$.
\end{abstract}

Keywords: Critical Temperature, FeSe superconductor, Magnesium-doped, Sintering, Solid-state Reaction

\section{PENDAHULUAN}

Ketergantungan manusia terhadap teknologi memasuki Revolusi Industri 4.0 sangatlah tinggi. Dengan adanya teknologi maka waktu dan tenaga manusia yang dibutuhkan semakin efisien. Kemajuan teknologi tidak terlepas dari peranan material yang mempunyai karakteristik berbedabeda. Salah satu material dengan karakteristik tersendiri yaitu material superkonduktor, yang diterapkan pada superkomputer karena memiliki kemampuan komputasi lebih besar daripada komputer biasa [1].

Material superkonduktor merupakan material dengan resistivitas (hambat jenis) listrik bernilai nol pada temperatur dibawah temperatur kritisnya (Tc), sehingga arus listrik dapat mengalir efisien [2]. Selain itu, material superkonduktor memiliki sifat diamagnetisme sempurna, yang artinya dapat menolak medan magnet. Oleh sebab itu, teknologi superkonduktor ini tumbuh pesat dan menjadi topik pembicaraan serta penelitian 
terpopuler yang terus dikembangkan oleh para peneliti dunia hingga saat ini karena manfaatnya yang sangat besar [3].

Material dengan sifat penghantar arus listrik yang baik identik dengan material dari unsur logam. Namun tidak semua unsur logam yang memiliki konduktor baik mempunyai sifat superkonduktor, terkecuali logam feromagnetik yang tidak dapat memiliki sifat superkonduktor karena dapat ditarik kuat oleh magnet. Salah satu contohnya adalah besi. Besi dapat mencemari sampel superkonduktor dengan adanya pengotor magnetik sehingga dapat menghancurkan sifat superkonduktivitas suatu material [4].

Penemuan material superkonduktor berbasis logam ferromagnetik / Fe oleh Kamihara dkk., mengejutkan dunia penelitian. Selama ini, material superkonduktor berbasis Fe bertentangan dengan superkonduktor konvensional yang diyakini bahwa material jenis Fe tidak pernah merangkap sebagai material superkonduktor. Penemuan material superkonduktor berbasis logam $\mathrm{Fe}$ ini membuktikan adanya sifat superkonduktor dengan mekanisme baru yang berbeda dari CuO [5].

Material FeSe merupakan salah satu material superkonduktor berbasis besi (Fe). Mayoritas material FeSe mempunyai temperatur kritis awal / onset $\left(\mathrm{Tc}_{\text {onset }}\right)$ sebesar $8 \mathrm{~K}$ dengan struktur kristal tetragonal $\beta$-FeSe [6]. Meskipun $\mathrm{Tc}_{\text {onset }}$ nya rendah, material FeSe mempunyai banyak keunggulan diantaranya yaitu material FeSe tidak mengandung elemen arsenik beracun, sifat mekanik lebih baik, mempunyai anisotropi rendah, medan kritis tinggi, medan ireversibilitas tinggi, dan mempunyai struktur kristal sederhana sehingga mudah dipelajari [7].

Terdapat beberapa parameter yang perlu diperhatikan pada material FeSe untuk memperoleh jenis struktur kristal tetragonal $\beta$-FeSe. Komposisi stoikiometri dan doping merupakan parameter yang paling berpengaruh pada pembuatan material superkonduktor FeSe, didukung dengan waktu dan temperatur pemanasan yang tepat. Apabila waktu dan temperatur pemanasan yang digunakan tidak tepat, maka fasa $\beta$-FeSe tidak terbentuk sehingga sifat superkonduktor FeSe tidak ada. Penentuan temperatur, waktu, dan laju pendinginan dari proses perlakuan panas / sintering berpengaruh dalam proses pembentukan fasa pada suatu material [8].

Pembuatan material paduan (alloy) dalam ilmu metalurgi bertujuan agar dapat memperbaiki atau menghubungkan beberapa sifat material sehingga diperoleh material paduan yang lebih unggul. Material superkonduktor dapat dipadukan dengan doping agar memiliki nilai Tc lebih unggul, yang dilakukan dengan cara menambahkan atau menyubstitusi atom-atom lain sebagai dopingnya ke dalam atom-atom asli superkonduktor [9]. Salah satunya ialah penambahan doping $\mathrm{Mg}$ pada material FeSe yang dilakukan dengan metode reaksi padatan [10]. Penambahan doping unsur Magnesium (Mg) dengan jumlah yang optimal diindikasikan dapat memasukkan konsentrasi elektron yang signifikan ke dalam material FeSe, dimana superkonduktivitas yang lebih baik dapat ditunjukkan [11].

Perlakuan panas dan metode pendinginan dapat memengaruhi pembentukan Tc dan struktur kristal suatu material superkonduktor, namun penelitian tentang penambahan unsur Magnesium (Mg) pada pembuatan material superkonduktor FeSe dengan metode reaksi padatan belum banyak dilakukan. Oleh sebab itu, penelitian ini dilakukan untuk menganalisis pengaruh penambahan doping unsur Mg pada sintesis material superkonduktor FeSe dengan metode reaksi padatan dalam tabung tertutup (Powder in Sealed Tube/PIST). Metode PIST dinilai lebih sederhana dan ekonomis karena tidak memerlukan perlakuan khusus, seperti proses pemvakuman saat sintering sampel dilakukan [12].

\section{METODOLOGI}

\section{Peralatan dan Bahan Penelitian}

\section{Peralatan}

Peralatan yang digunakan dalam penelitian ini terdiri dari dua kelompok peralatan yaitu untuk pembuatan sampel dan untuk pengujian sampel. Peralatan pembuatan sampel yaitu diantaranya:

1. Timbangan digital

Timbangan digital digunakan untuk menimbang serbuk Mg, Fe, dan Se yang akan digunakan.

2. Mortar Agate dan Pesle

Mortar Agate dan Pesle digunakan untuk mencampur dan menggerus serbuk $\mathrm{Mg}, \mathrm{Fe}$, dan Se yang akan digunakan.

3. Spatula

Spatula digunakan untuk mengambil serbuk Mg, Fe, dan Se dari dalam wadahnya. Selain itu, spatula juga digunakan untuk membantu sampel $\mathrm{Mg}_{\mathrm{x}} \mathrm{Fe}_{1-\mathrm{x}}$ Se yang telah digerus kedalam tabung.

4. Combustion boat

Combustion boat digunakan agar sampel yang terbungkus didalam tabung mudah dimasukkan dan dikeluarkan dari tube furnace.

5. Tube furnace

Tube furnace digunakan untuk proses sintering sampel.

6. Gergaji besi

Gergaji besi digunakan untuk memotong segel tabung SS316 setelah proses sintering untuk memperoleh sampel $\mathrm{Mg}_{\mathrm{x}} \mathrm{Fe}_{1-\mathrm{x}} \mathrm{Se}$ yang tersegel tabung SS316 tersebut.

\section{Pinset}

Pinset digunakan untuk mengeluarkan sampel dari dalam kemasan tabung SS316.

8. Penjepit

Penjepit digunakan untuk membantu mengeluarkan sampel agar dapat dikeluarkan dari tube furnace setelah proses sintering.

9. Mesin tekan (press)

Mesin tekan digunakan untuk proses kompaksi sampel didalam tabung SS316. 


\section{PCB Holder}

$P C B$ Holder digunakan sebagai wadah sampel untuk dilakukan uji Resistivitas didalam tabung Cryogenic Magnet.

\section{Pengujian}

1. Mesin uji XRD

Komposisi fasa sampel yang telah disintering dikarakterisasi dengan cara difraksi sinar-X menggunakan XRD X'Pert $M P D$, dengan sumber radiasi $\mathrm{CuK \alpha}$.

2. Mesin uji SEM

Pengamatan morfologi sampel dilakukan menggunakan alat SEM JEOL tipe JSM-6390A dengan sinyal Secondary Electron.

3. Mesin uji Resistivitas

Resistansi sampel diukur menggunakan metode Four-point Probe dengan alat Cryogenic Magnet "Teslatron PT" buatan Oxford.

\section{Bahan}

1. Serbuk Magnesium (Mg)

Serbuk Magnesium (Mg) merupakan bahan yang digunakan dalam pembuatan sampel penelitian.

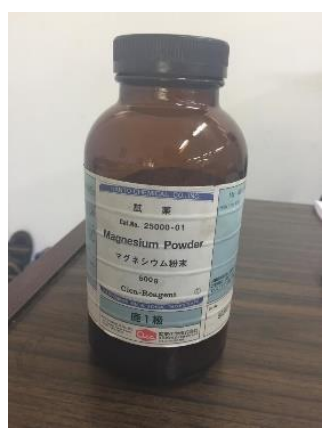

Gambar 1. Serbuk Magnesium (Mg)

2. Serbuk Besi (Fe)

Serbuk Besi $(\mathrm{Fe})$ merupakan bahan yang digunakan dalam pembuatan sampel penelitian.

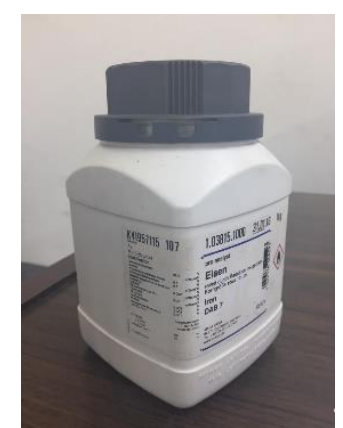

Gambar 2. Serbuk Besi (Fe)

3. Serbuk Selenium (Se)

Serbuk Selenium (Se) merupakan bahan yang digunakan dalam pembuatan sampel penelitian.

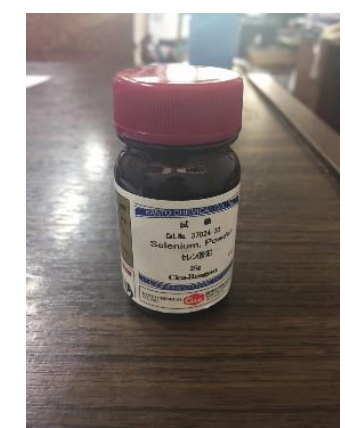

Gambar 3. Serbuk Selenium (Se)

4. Tabung Stainless Steel (SS) 316

Tabung Stainless Steel (SS) 316 digunakan sebagai tempat sampel penelitian.

5. Pasta Perak (Ag)

Pasta Perak (Ag) merupakan bahan yang digunakan untuk merekatkan sampel pada $P C B$ Holder.

6. Gas Helium

Gas Helium digunakan untuk menurunkan temperatur sampel hingga mencapai $1.5 \mathrm{~K}$.

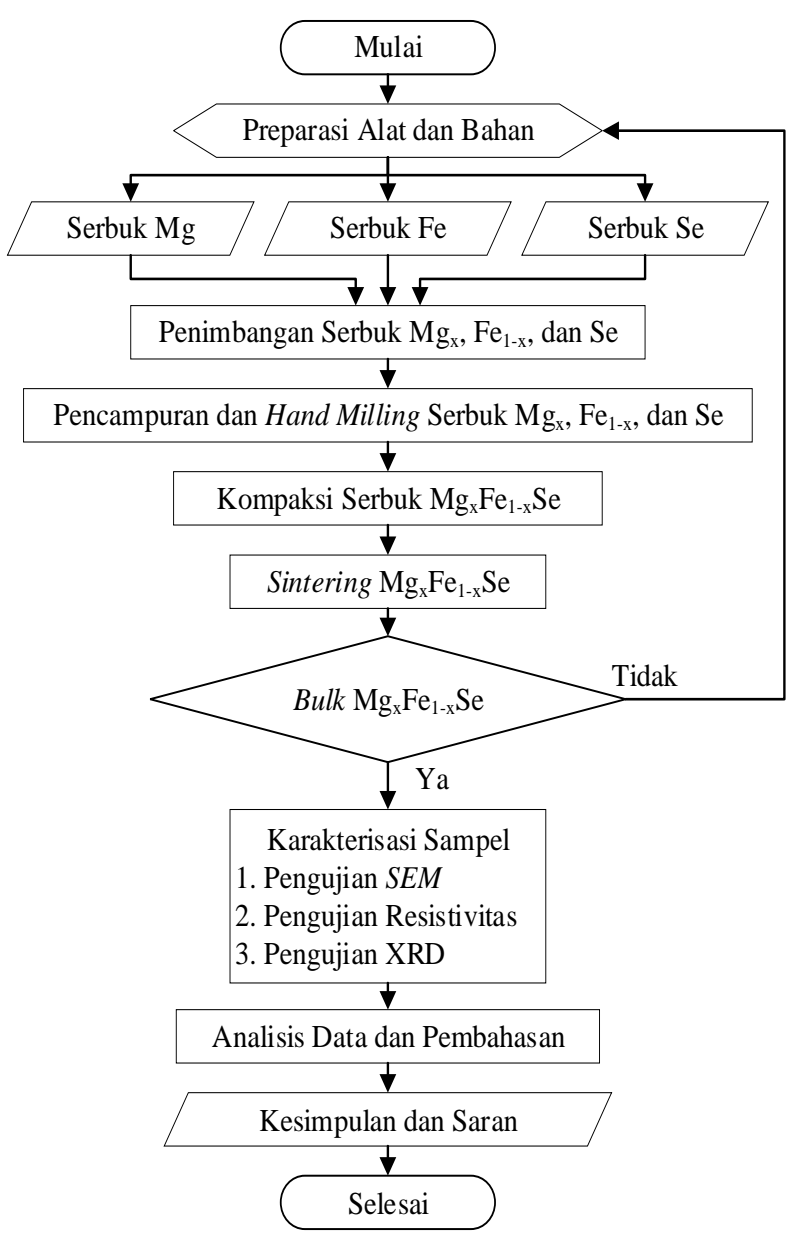

Gambar 4. Diagram Alir Penelitian

Sampel $\mathrm{Mg}_{\mathrm{x}} \mathrm{Fe}_{1-\mathrm{x}} \mathrm{Se}(\mathrm{x}=0,0.01,0.05,0.1$ ) bulk polikristalin dibuat dengan metode reaksi padatan dari serbuk Besi (kemurnian $\mathrm{Fe}=99 \%$ ) dan serbuk Selenium (kemurnian $\mathrm{Se}=99 \%$ ), yang didoping 
dengan serbuk Magnesium (kemurnian $\mathrm{Mg}=98 \%$ ). Proses pencampuran serbuk $\mathrm{Fe}$, Se, dan $\mathrm{Mg}$ dilakukan dengan cara hand milling menggunakan mortar agate dan pesle selama 3 jam. Campuran serbuk tersebut dikemas ke dalam tabung Stainless Steel (SS) 316 berdiameter $6 \mathrm{~mm}$ dengan panjang $80 \mathrm{~mm}$. Ujung tabungnya ditutup dengan cara diberi tekanan. Lalu, sampel $\mathrm{Mg}_{\mathrm{x}} \mathrm{Fe}_{1-\mathrm{x}} \mathrm{Se}$ didalam tabung SS316 yang telah tersegel tersebut dikompaksi dengan tekanan $1000 \mathrm{KPa}$. Semua sampel yang telah dikemas didalam tabung SS316 diletakkan pada combustion boat dan disintering didalam tube furnace. Temperatur sintering yang digunakan $845^{\circ} \mathrm{C}$ dengan kenaikan temperatur $7^{\circ} \mathrm{C} /$ menit dari temperatur kamar, dan kemudian ditahan selama 6 jam, dengan laju pendinginan normalizing.

\section{HASIL DAN DISKUSI}

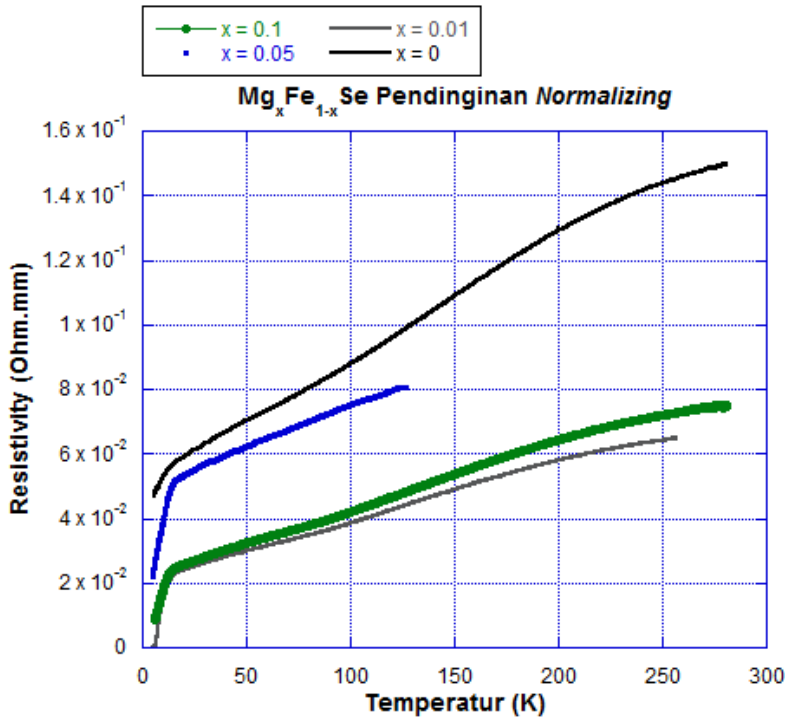

Gambar 5. Grafik Hubungan Resistivitas dan Temperatur Sampel $\mathrm{Mg}_{\mathrm{x}} \mathrm{Fe}_{1-\mathrm{x}} \mathrm{Se}$

Gambar 5 menunjukkan ketergantungan resistivitas terhadap perubahan temperatur yang diberikan pada sampel $\mathrm{Mg}_{\mathrm{x}} \mathrm{Fe}_{1-\mathrm{x}} \mathrm{Se}(\mathrm{x}=0,0.01,0.05$, 0.1 ) hasil proses sintering. Kemiringan resistivitas $(\rho)$ mengindikasikan sampel tersebut menunjukkan perilaku logam. Sampel yang didoping Mg memiliki resistivitas lebih rendah dibandingkan sampel tanpa doping $\mathrm{Mg}$ dari keadaan normal hingga temperatur rendah. Selain itu, sampel yang didoping $\mathrm{Mg}$ memiliki fenomena superkonduktor yang lebih baik, ditandai dengan penurunan resistivitas yang lebih curam pada temperatur rendah. Sampel FeSe tanpa doping $\mathrm{Mg}$ memiliki $\mathrm{Tc}_{\text {onset }}=14.22 \mathrm{~K}$, disertai dengan $\mathrm{Tc}_{\mathrm{zero}}$ yang belum tercapai. Sampel $\mathrm{Mg}_{0.01} \mathrm{Fe}_{0.99}$ Se memiliki $\mathrm{Tc}_{\text {onset }}=15.42 \mathrm{~K}$ dan $\mathrm{Tc}_{\text {zero }}=$ $5.40 \mathrm{~K}$, dengan nilai $\Delta \mathrm{Tc}=10.02 \mathrm{~K}$. Sampel $\mathrm{Mg}_{0.05} \mathrm{Fe}_{0.95} \mathrm{Se}$ memiliki $\mathrm{Tc}_{\text {onset }}=14.55 \mathrm{~K}$, disertai dengan $\mathrm{Tc}_{\mathrm{zero}}$ yang belum tercapai. Sampel $\mathrm{Mg}_{0.1} \mathrm{Fe}_{0.9} \mathrm{Se}$ memiliki $\mathrm{Tc}_{\text {onset }}=14.44 \mathrm{~K}$, disertai dengan $\mathrm{Tc}_{\text {zero }}$ yang belum tercapai. Mekanisme peningkatan dalam Tc sampel FeSe yang didoping unsur Mg ini dapat diklarifikasi lebih lanjut dari komposisi fasa dan struktur mikro yang terbentuk.

Gambar 6 menunjukkan pola difraksi sinar-X dari sampel $\mathrm{Mg}_{\mathrm{x}} \mathrm{Fe}_{1-\mathrm{x}} \mathrm{Se}(\mathrm{x}=0,0.01,0.05,0.1$ ) hasil proses sintering. Dari Gambar 6 terlihat bahwa fasa superkonduktor $\beta$-FeSe merupakan fasa utama dalam semua sampel yang telah disintering. Dengan penambahan doping Mg pada sampel FeSe, intensitas puncak $\beta$-FeSe menurun pada sampel $\mathrm{Mg}_{0.01} \mathrm{Fe}_{0.99} \mathrm{Se}$. Akan tetapi, intensitas puncak $\beta$-FeSe kembali meningkat ketika doping $\mathrm{Mg}$ ditambahkan dari sampel $\mathrm{Mg}_{0.01} \mathrm{Fe}_{0.99}$ Se ke sampel $\mathrm{Mg}_{0.1} \mathrm{Fe}_{0.9} \mathrm{Se}$, yang disertai kemunculan puncak dari fasa MgSe dan Fe yang secara bertahap menjadi lebih tajam. Namun, doping unsur Mg jarang masuk ke dalam kisi kristal dari $\beta$-FeSe dan juga jarang menyubstitusi Fe. Berdasarkan hasil XRD, dapat disimpulkan bahwa penambahan doping $\mathrm{Mg}$ sebagian besar bereaksi dengan material FeSe membentuk fasa MgSe dan Fe:

$$
\mathrm{Mg}+\mathrm{FeSe} \rightarrow \mathrm{MgSe}+\mathrm{Fe}
$$

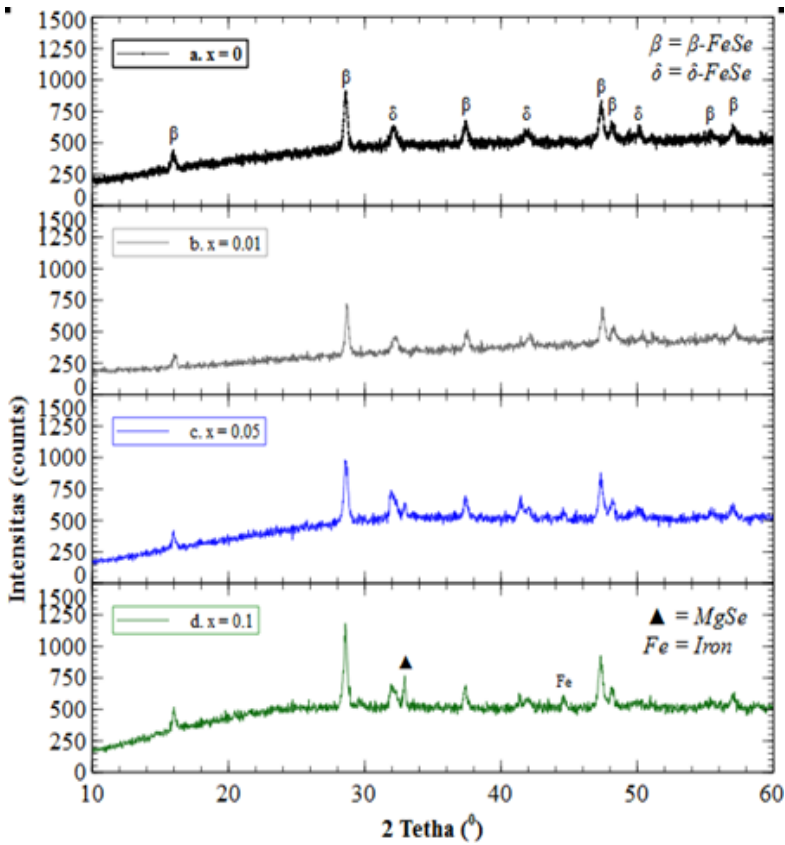

Gambar 6. Pola Difraksi Sinar-X Sampel $\mathrm{Mg}_{\mathrm{x}} \mathrm{Fe}_{1-\mathrm{x}} \mathrm{Se}$

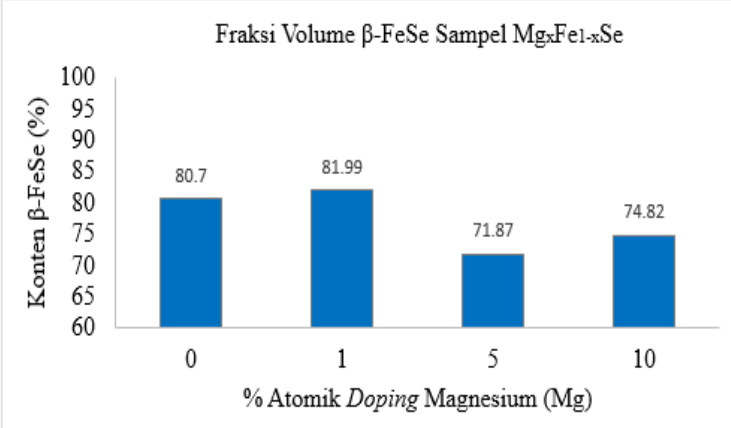

Gambar 7 Fraksi Volume $\beta$-FeSe Sampel $\mathrm{Mg}_{\mathrm{x}} \mathrm{Fe}_{1-\mathrm{x}} \mathrm{Se}$

Gambar 8 menunjukkan gambar SEM dari sampel $\mathrm{Mg}_{\mathrm{x}} \mathrm{Fe}_{1-\mathrm{x}} \mathrm{Se}(\mathrm{x}=0,0.01,0.05,0.1$ ) hasil 
proses sintering. Dapat dilihat bahwa sampel FeSe tanpa penambahan doping $\mathrm{Mg}$ pada Gambar 8a memiliki porositas yang cukup besar. Dengan penambahan doping $\mathrm{Mg}$, sampel $\mathrm{Mg}_{0.01} \mathrm{Fe}_{0.99} \mathrm{Se}$ memperlihatkan morfologi permukaan dengan kristalisasi yang besar berbentuk bongkahanbongkahan halus yang tersebar di permukaan sampel (dapat dilihat pada Gambar 8b). Namun, penamambahan doping Mg yang lebih besar seperti pada sampel $\mathrm{Mg}_{0.1} \mathrm{Fe}_{0.9}$ Se menyebabkan aglomerasi (gumpalan-gumpalan) partikel pada morfologi sampel $\mathrm{Mg}_{0.1} \mathrm{Fe}_{0.9} \mathrm{Se}$ tersebut (dapat dilihat pada Gambar 8d) karena ukuran partikel unsur Mg yang lebih besar dibandingkan dengan partikel unsur Fe dan Se. Ukuran partikel yang mengecil akan meningkatkan rasio permukaan atau volume sehingga aglomerasi dapat terjadi.
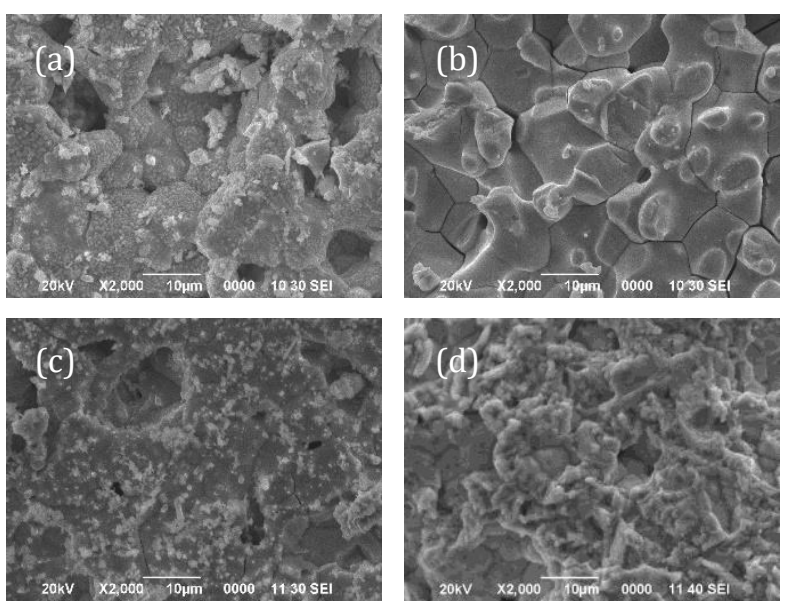

Gambar 8. Hasil SEM Sampel $\mathrm{Mg}_{\mathrm{x}} \mathrm{Fe}_{1-\mathrm{x}} \mathrm{Se}$

(a) FeSe (b) $\mathrm{Mg}_{0.01} \mathrm{Fe}_{0.99} \mathrm{Se}$

(c) $\mathrm{Mg}_{0.05} \mathrm{Fe}_{0.95} \mathrm{Se}$ (d) $\mathrm{Mg}_{0.1} \mathrm{Fe}_{0.9} \mathrm{Se}$

Grafik hubungan resistivitas dan temperatur sampel $\mathrm{Mg}_{\mathrm{x}} \mathrm{Fe}_{1-\mathrm{x}} \mathrm{Se}$ menunjukkan bahwa dengan penambahan doping $\mathrm{Mg}$ dapat menyebabkan penurunan resistivitas lebih rendah pada sampel FeSe. Sampel $\mathrm{Mg}_{0.01} \mathrm{Fe}_{0.99} \mathrm{Se}$ merupakan kandidat sampel terbaik dari semua sampel material karena hanya satu-satunya sampel yang mencapai $\mathrm{Tc}_{\text {zero. }}$. Hal ini selaras dengan hasil difraksi sinar-X yang tidak menunjukkan kehadiran fasa MgSe dan Fe pada sampel material $\mathrm{Mg}_{0.01} \mathrm{Fe}_{0.99} \mathrm{Se}$, ditambah hasil persentase fraksi volume fasa superkonduktornya juga merupakan yang terbesar yaitu $81.99 \%$, yang dapat dilihat pada Gambar 7. Selain itu, penambahan doping $\mathrm{Mg}$ menyebabkan morfologi pada sampel $\mathrm{Mg}_{0.01} \mathrm{Fe}_{0.99} \mathrm{Se}$ mengalami pembentukan kristalisasi yang besar, karena MgSe yang muncul mempunyai karakteristik difraksi sinar-X hampir mirip dengan $\beta$-FeSe sehingga MgSe dapat masuk kedalam matriks $\beta$-FeSe, yang akhirnya membentuk struktur butir yang baru.

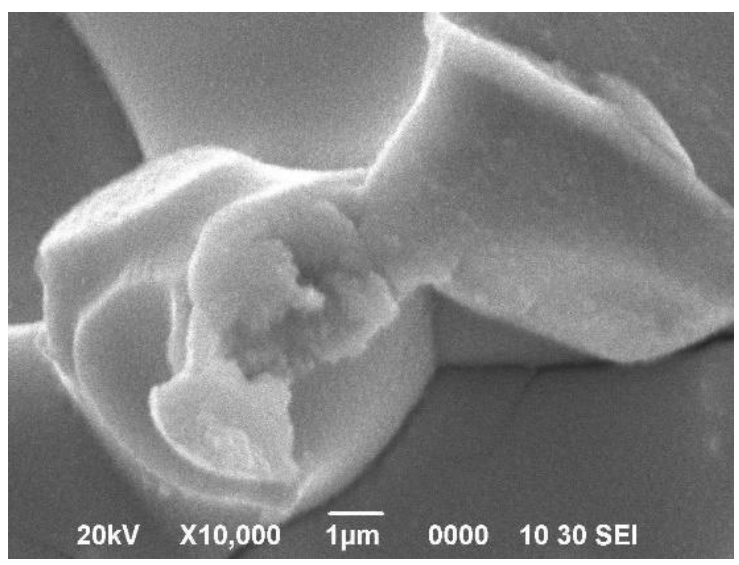

Gambar 9. Hasil SEM Sampel $\mathrm{Mg}_{0.01} \mathrm{Fe}_{0.99} \mathrm{Se}$ Perbesaran $10.000 \mathrm{X}$

Spekulasi ini selanjutnya dapat dibuktikan dengan pemetaan unsur $\mathrm{Se}, \mathrm{Fe}$ dan $\mathrm{Mg}$ dengan pengujian SEM mapping pada Gambar 10. Dari Gambar 10 dapat dilihat bahwa Fe terdistribusi secara seragam dalam keseluruhan gambar SEM, sementara Mg dan Se relatif terkonsentrasi di dalam lapisan butir,
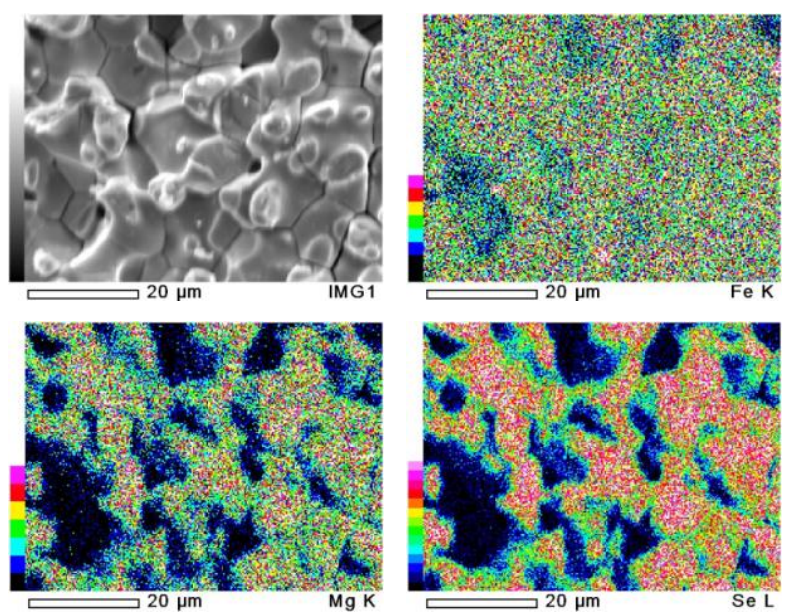

Gambar 10. Mapping Unsur Fe, Se, dan Mg pada Morfologi Sampel $\mathrm{Mg}_{0.01} \mathrm{Fe}_{0.99} \mathrm{Se}$

Menurut Wenbin Qiu dkk tahun 2016, penambahan doping Magnesium (Mg) pada material superkonduktor FeSe terindikasi dapat menginduksi variasi konsentrasi pembawa elektron dan memasukkan doping elektron, yang dapat memengaruhi kinerja superkonduktor akhir dalam material FeSe secara signifikan. Penambahan doping Mg jarang masuk ke dalam kisi kristal dari fasa $\beta$ FeSe dan juga jarang menyubstitusi Fe [10] sehingga penambahan doping $\mathrm{Mg}$ yang optimal dapat memiliki efek dan dampak positif terhadap kinerja material superkonduktor FeSe. Akan tetapi, degradasi atau bahkan keruntuhan dapat terjadi pada sifat superkonduktivitas FeSe apabila kandungan doping $\mathrm{Mg}$ berlebih dimasukkan ke dalam material FeSe tersebut [13]. 


\section{KESIMPULAN}

Pada penelitian ini dapat disimpulkan bahwa penambahan doping Magnesium (Mg) mempunyai pengaruh positif terhadap sifat superkonduktor material FeSe, dimana penambahan doping $\mathrm{Mg}$ dapat menurunkan resistivitas material FeSe menjadi lebih rendah. Hasil dari penelitian ini adalah nilai optimum doping Mg pada material FeSe terdapat pada sampel $\mathrm{Mg}_{0.01} \mathrm{Fe}_{0.99}$ Se. Didapatkan nilai Temperatur kritis (Tc) onset yang diperoleh $15.42 \mathrm{~K}$ dan $\mathrm{Tc}_{\text {zero }}$ yang diperoleh $5.4 \mathrm{~K}$. Morfologi sampel $\mathrm{Mg}_{0.01} \mathrm{Fe}_{0.99} \mathrm{Se}$ menunjukkan kristalisasi besar dari semua sampel penelitian. Lalu, persentase fraksi volume fasa superkonduktor $(\beta$ FeSe) sampel $\mathrm{Mg}_{0.01} \mathrm{Fe}_{0.99} \mathrm{Se}$ juga merupakan yang terbesar dari semua sampel, yaitu $81.99 \%$. Penelitian selanjutnya diperlukan variasi metode pembuatan (milling processes), variasi proses sintering (temperatur, waktu tahan, dan laju pendinginan), dan variasi tekanan yang digunakan saat proses kompaksi sampel didalam tabung tertutup untuk mengetahui efek superkonduktivitas lebih lanjut.

\section{UCAPAN TERIMA KASIH}

Penulis mengucapkan terima kasih kepada Pemerintah Republik Indonesia melalui Penguatan Kompetensi Pusat Penelitian Metalurgi dan Material (P2MM), Lembaga Ilmu Pengetahuan Indonesia (LIPI) 2019.

\section{REFERENSI}

[1] C. M. Arista dan M. A. Baqiya, "Sintesis dan Karakterisasi Polikristal Superkonduktor FeSe-Te dengan Reaksi Padatan dalam Kondisi Vakum," SAINS DAN SENI ITS, vol. 4, no. 1, pp. 1-5, 2018.

[2] W. D. Callister dan D. G. Rethwisch, Materials Science and Engineering, 9 penyunt., New York: John Wiley and Sons, inc, 2014.

[3] Nurmalita, "The Effect of Pb Dopant on The Critical Temperature of BSCCO-2212 Superconducting Crystal," Proceedings of The 2nd Annual International Conference Syiah Kuala University 2012, pp. 396-402, 2012.

[4] P. Hofmann, Solid State Physics, Edisi ke 2, Weinheim: Wiley-VCH, 2015.

[5] Y. Kamihara, T. Watanabe, M. Hirano dan H. Hosono, "Iron-Based Layered Superconductor $\mathrm{La}[01-\mathrm{xFx}] \mathrm{FeAs}$ (x ) 0.050.12 ) with Tc $=26 \mathrm{~K}, "$ J. AM. Chem. Soc, vol. 130, no. 11, pp. 3296-3297, 2008.

[6] F.-C. Hsu, J.-Y. Luo, K.-W. Yeh, T.-K. Chen, T.W. Huang, P. M. Wu, Y.-C. Lee, Y.-L. Huang, Y.Y. Chu, D.-C. Yan dan M.-K. Wu, "Superconductivity in the PbO-type Structure
$\alpha$-FeSe," PNAS, vol. 105 , no. No. 38, pp. 14262-14264, 2008.

[7] Y. P. Dewi, Pengaruh Komposisi Pada Sifat Struktur dan Superkonduktivitas $\mathrm{Fe}(\mathrm{Se}, \mathrm{Te})$ Dipreparasi dengan Metode Metalurgi Serbuk, Surabaya: Perpustakaan UNAIR, 2016.

[8] T. Mousavi, C. R. M. Grovenor dan S. Speller, "Structural Parameters Affecting Superconductivity in Iron Chalcogenides: a Review," Materials Science and Technology, vol. 30, no. No. 15, pp. 1929-1943, 2014.

[9] Y. P. Dewi, Analisis Pengaruh Metode Pembuatan, Temperatur Sintering, dan Doping Carbon Nanotubes pada Mikrostruktur dan Superkonduktivitas MgB2, Surabaya: ITS, 2018.

[10] F. Lan, Z. Ma, Y. Liu, N. Chen, Q. Cai, H. Li, S. Barua, D. Patel, M. S. A. Hossain, J. H. Kim dan S. X. Dou, "The formation of nano-layered grains and their enhanced superconducting transition temperature in $\mathrm{Mg}$-doped $\mathrm{FeSe} 0,9$ bulks," Scientific Reports, pp. 1-5, 2014.

[11] G. Zhou, Q. Zhang, F. Zheng, D. Zhang, C. Liu, X. Wang, C.-L. Song, K. He, X.-C. Ma, L. Gu, P. Zhang, L. Wang dan Q.-K. Xue, "Interface enhanced superconductivity in monolayer FeSe films on $\mathrm{MgO}(001)$ : charge transfer with atomic substitution," Science Bulletin, pp. 119, 2018.

[12] R. Fitriandhani, Pengaruh Variasi Suhu Sintering dan Komposisi Stoikiometri Terhadap Pembentukan Fasa $\beta$-FeSe Melalui Pemaduan Mekanik dan Proses Reaksi Padatan, Jakarta: STT PLN, 2019.

[13] W. Qiu, Z. Ma, Y. Liu, M. S. A. Hossain, X. Wang, C. Cai dan S. X. Dou, "Tuning Superconductivity in FeSe Thin Films via Magnesium Doping," ACS Applied Materials and Interfaces, vol. VIII, no. 12, pp. 78917896, 2016.

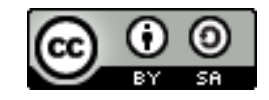

This is an open access article which means that all content is freely available without charge to the user or his/her institution. Jurnal Saintis allows the author(s) to hold the copyright without restriction. The copyright in the text of individual rticles (including research article, opinion articles, and abstracts) is the property of their respective authors distriuted under the terms of the Creative Commons Attribution-ShareAlike 4.0 International License (http://creativecommons.org/licenses/by-sa/4.0/) which permits unrestricted use, distribution, and reproduction in any medium. Users are allowed to read, download, copy, distribute, search, or link to full-text articles in this journal without asking by giving appropriate credit, provide a link to the license, and indicate if changes were made. 